\title{
Infusing Energy Efficient Illumination Design to retrofit existing infrastructures - A case of energy-efficient illumination design of Multipurpose Hall at Jigme Namgyel Engineering College
}

\author{
*Hemlal Bhattarai ${ }^{1}$, Abhishek Pokhrel ${ }^{2}$, Sarda Chuwan ${ }^{3}$, Abiskar Chhetri ${ }^{4}$, Chimi Dem ${ }^{5}$ \\ ${ }^{* 1}$ Centre for Lighting and Energy Efficiency Studies (CLEES), Jigme Namgyel Engineering College, Bhutan \\ b.hemlal@gmail.com 0000-0002-6512-1685 \\ 2,3,4BEPE, Jigme Namgyel Engineering College, Bhutan \\ ${ }^{5}$ Faculty, Department of Electrical Engineering, Jigme Namgyel Engineering College, Bhutan
}

\section{HIGHLIGHTS}

- Illumination requirements need to be considered

- A clear understanding of illumination requirements of workspace is vital always

- Incorporating mixed design for enhanced comfort as well as productivity

- Multiple options need to be explored so as to retrofit.

\section{Keywords:}

- Illumination design

- Energy Efficient Lighting

- Natural Lighting

- Problem Based Learning

- Multipurpose Hall

Article Info:

Received: 13 December 2021 Accepted: 18 December 2021 Published: 21 December 2021

DOI: $10.53525 /$ jster. 1035864

\section{*Correspondence:}

Hemlal Bhattarai b.hemlal@gmail.com

\section{GRAPHICAL ABSTRACT}

As illumination design is crucial for visual requirements and comfort as well as enhancing productivity, its consideration needs to be critical. Due to technological changes as well as the availability of energy-efficient luminaries in the market, the designers and implementers need to take advantage of these and make needful incorporation in new infrastructures or retrofits of the existing infrastructures. The energy consumption from lighting is quite significant and efforts have been in a switch to more energy-efficient luminaires. On top of this, the education campus is one significant contributor to maximum energy consumptions from lighting. As a result, the design needs to holistically look into illumination design based on a standard to meet the illumination requirements of a given workplace keeping in mind of possible incorporation of natural light and energy-efficient luminaires. Substantial illumination especially can be derived from natural light which was not seriously taken into consideration in old infrastructures thus rectifying and retrofits needs to explore best of the best options.
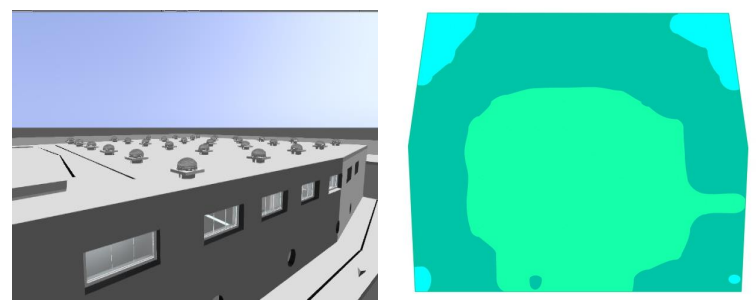

Figure A. a) MPH with 30 light tunnels arrangement, b) Light distribution on auditoria

Aim of Article: This research is to understand the existing lighting conditions of the Multipurpose Hall (MPH) of Jigme Namgyel Engineering College, and come up with the findings for the measures that can be derived for interventions.

Theory and Methodology: The study incorporated 'Problem Based Learning (PBL)' methodology from problem scanning, problem framing, data collections and analysis along with possible recommendations. The use of primary as well as secondary data in this research which is qualitative in nature is the base for overall research. Also 'Post Occupancy Evaluation (POE)' approaches are incorporated in data collections so that realistic understandings and necessary measures can be taken in the study.

Findings and Results: It is evident from the study that the current lighting conditions of MPH under the study are having significance lacking in its illumination requirements. There are immediate needs felt for interventions so as to derive the maximum benefits of the infrastructures without compromising the comfort of the users. The study also explored that there are multiple options that can be incorporated for the needful.

Conclusion: Existing infrastructures can be retrofits using multiple options so that visual comforts, as well as the productivity of users, can be enhanced from usages of given working spaces. 


\title{
Infusing Energy Efficient Illumination Design to retrofit existing infrastructures - A case of efficient illumination design of Multipurpose Hall at Jigme Namgyel Engineering College
}

\author{
${ }^{*}$ Hemlal Bhattarai ${ }^{1}$, Abhishek Pokhrel ${ }^{2}$, Sarda Chuwan $^{3}$, Abiskar Chhetri ${ }^{4}$, Chimi Dem ${ }^{5}$ \\ ${ }^{* 1}$ Centre for Lighting and Energy Efficiency Studies (CLEES), Jigme Namgyel Engineering College, Bhutan \\ b.hemlal@gmail.com 0000-0002-6512-1685 \\ ${ }^{2,3,4}$ BEPE, Jigme Namgyel Engineering College, Bhutan \\ ${ }^{5}$ Faculty, Department of Electrical Engineering, Jigme Namgyel Engineering College, Bhutan
}

\begin{abstract}
Citation:
Bhattarai, H., Pokhrel, A., Chuwan, S., Chhetri, A., Dem, C., (2021). The Problems Encountered in the Process of Publishing Articles in the Journal and Investigation of the Solutions, Journal of Scientific Technology and Engineering Research, 2(2):89100. DOI: $10.53525 /$ jster. 1035864
\end{abstract}

\section{H I G H L I G H T S}

- Illumination requirements need to be considered for the given workplace for visual comfort and productivity

- A clear understanding of illumination requirements of workspace vital always for design and retrofits

- Incorporating mixed design for enhanced visual comfort as well as productivity

- Multiple options need to be explored for design and retrofit for better implementations.

\section{Article Info}

Received: 13 December 2021

Accepted: 18 December 2021

Published: 21 December 2021

DOI: $10.53525 /$ jster. 1035864

\section{*Corresponding Author:}

Hemlal Bhattarai

b.hemlal@gmail.com

Phone: +97517623426

\begin{abstract}
Illumination design is a very important part of any infrastructure. The level of illumination for various workspace requirements are different and it is crucial to calculate the required level of illumination for new as well as existing infrastructures. Furthermore, the usage of natural light, as well as energy-efficient luminaries, are considered to be the preferred choices in illumination design. In this study, the illumination design of one of the most frequent infrastructures (i.e. Multipurpose Hall $(\mathrm{MPH})$ ) has been studied incorporating the 'Problem Based Learning (PBL)' approaches where actions on problem scanning, working on the problem and coming up with multiple solutions to counter the realistic problem were looked into. The study which is more qualitative in nature is backed by primary as well as secondary data to study the problems and frame multiple options of recommendation for retrofits that can be incorporated in enhancing the illumination level through energy-efficient illumination design as well as integration of natural light where possible.
\end{abstract}

Keywords: Illumination design, Energy Efficient Lighting, Natural Lighting, Problem Based Learning, Multipurpose Hall

\section{INTRODUCTION}

Illumination of working space is crucial and achieving the desired level of illumination on the working plane is the most sought aspect in illumination design. In general, the amount of illuminance received on the working plane has a significant impact on productivity. The optimum illumination is met when the right luminary is placed properly. However, in implementing the design, often, the luminaries chosen while designing are not locally available and/or are too impractical because of its cost and many a time it is ignored to be implemented as designed. Every infrastructure and its amenities will have various levels of illumination level as recommended. A target for the lighting system to become efficient is also a 
consideration of daylight along with artificial lighting. The idea behind energy-efficient architecture is to optimize the lighting system by incorporating natural and artificial illumination.

Furthermore, more than any other type of building, daylighting is a critical consideration in the design of educational institutions [1]. Researches working on the field of indoor illumination highlighted that ensuring lighting quality in an educational environment is a rather tedious task particularly due to glare calculation. Glare calculations are an important aspect in terms of visual comfort but are usually avoided in most lighting designs due to their complexity. The lighting performances of different buildings under different conditions, activities on given amenities involving different methods were carried out to understand the lighting distribution. Those researches were carried out also to find how the position and the alignment of a structure, use of different luminaires affect the amount of light received on the working plane. However, not much study was done to the improving the lighting system in any structure by considering the daylight [2]. A study was done on efficient illumination design of some of the most energy-consuming buildings in an educational institute and concluded that the choice of lamp can greatly affect energy consumption for the same illumination [3].

Some critical studies on lighting performances done at various places are;

- The natural lighting for energy is saving and visual comfort in collective housing: A case study in the Algerian building context. In this research, much focus was given to the visual comfort of the occupants. Post Occupancy Evaluation (POE) was employed [4].

- Assessment of natural lighting performance and visual comfort of educational architecture in southern Europe. The case of typical educational school premises in Cyprus. This paper is like the earlier paper. However, it acknowledges the fact that daylighting is more important in an educational facility rather than artificial lighting [5].

A study of Analysis of natural light distribution in Phinisi tower was carried out mainly to study how the position, floor height and window openings of a building affect the distribution of natural light. This research has not used any software instead they have manually measured the illumination level for different rooms in the building for the different hours of a day for three days. It was found out that the level of daylight depends on the sky condition and it has affected the light distribution into the building. The window opening and the height of the building after the illuminance of a room. And it was found out that the distribution of natural light increases during the day if the sky condition does not change [6]. The influence of natural light on the design of electrical lighting-Taking Liaohe Art Museum as an example. It was concluded that the integration of natural light and artificial light brings better psychological effects. The European Standard EN12665:2011 defines visual comfort as a subjective state of visual well-being caused by the visual environment [7]. Visual comfort depends on (i) the physiology of the human eye, (ii) the physical quantities describing the amount of light and its distribution in space, and (iii) the spectral emission of the light source. It has been commonly studied through the assessment of a series of factors regulating the relationship between the human needs and the light environment, such as (i) the amount of light, (ii) the uniformity of light, (iii) the quality of light, and (iv) the occurrence of glare [8]. According to the current regulations and specifically the internal house wiring standards-safety specifications of Bhutan [9], the recommended values of illumination in lux for relevant areas are as tabled.

Table 1. Required illumination level for various amenities

\begin{tabular}{|l|l|}
\multicolumn{1}{|c|}{ Area } & \multicolumn{1}{c|}{$\begin{array}{c}\text { Illumination } \\
\text { in lux }\end{array}$} \\
\hline $\begin{array}{l}\text { Assembly hall in educational } \\
\text { centers }\end{array}$ & 150 \\
\hline Corridor & 70 \\
\hline Stairs & 100 \\
\hline Stage (Displays) & $200-300$ \\
\hline Printing press & 300 \\
\hline
\end{tabular}

Unified Glare Rating (UGR) is an indicator of direct glare from the luminaries of a lighting system. A UGR of 10 is considered as no glare and a UGR of 30 is considered as unacceptable discomfort glare [10]. Therefore, a UGR of 19-22 can be considered acceptable as achieving no glare is practically impossible. 
One indicator of daylight performance is the Daylight Factor (DF). This is the most widely used index which defines the ratio of interior luminance on a horizontal surface to the exterior illuminance on a horizontal surface under an overcast sky. According to BREEAM standards, the minimum DF should be at least $2 \%$ for $80 \%$ of the space. A Multipurpose Halls (MPH) in the educational campus is the most frequent usage of amenities and is one of the high energy consumers due to numerous activities taking place in it. Researchers pointed out that MPHs in institutes contribute almost $20 \%$ to $30 \%$ of the total energy consumption where the share of lighting is significant [11].

\section{STUDY UNDER CONSIDERATION}

A. Study site and the solar context of the location

In understating the illumination design role of natural light plays a significant role. Hence it is crucial to understand the cloud coverage of the location. The cloud coverage of the region as referred from 'Weather Spark' [12] is shown below in figure 1 where their average of 2013-2021 is being reported.

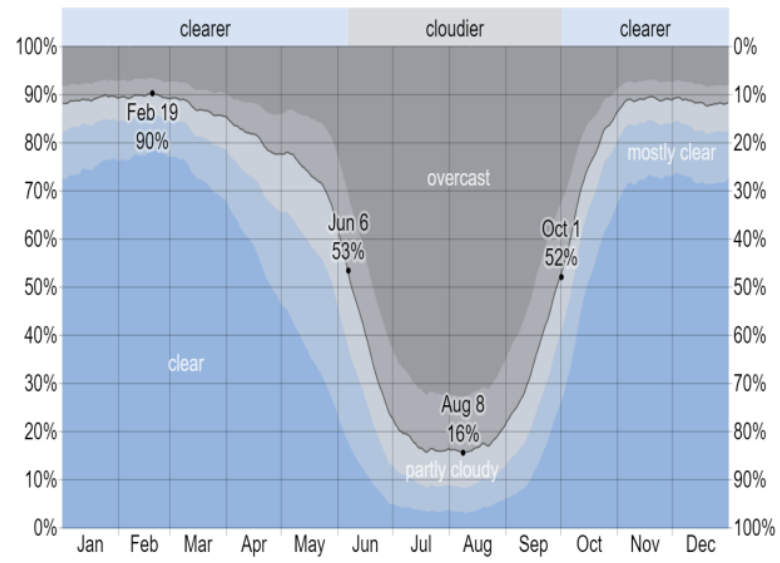

Figure 1. Cloud coverage of the region (Samdrup Jongkhar) [12]

From the figure above, it is evident that;

i. The average percentage of the sky covered by clouds experiences extreme seasonal variation over the course of the year.

ii. The clearer part of the year begins around September 30 and lasts for 8.2 months, ending around June 5. On February 19, the clearest day of the year, the sky is clear, mostly clear, or partly cloudy $90 \%$ of the time, and overcast or mostly cloudy $10 \%$ of the time.

iii. The cloudier part of the year begins around June 5 and lasts for 3.8 months, ending around September 30. On August 7, the cloudiest day of the year, the sky is overcast or mostly cloudy $84 \%$ of the time and clear, mostly clear, or partly cloudy $16 \%$ of the time.

iv. The length of the day varies over the course of the year. In 2020, the shortest day is December 21, with 10 hours, 27 minutes of daylight; the longest day is June 21, with 13 hours, 50 minutes of daylight.

\section{B. Study site (Multipurpose Hall of the College)}

The MPH understudy of this study consists of three construction moduli. As depicted in Figure 2 below, the three construction moduli as follow:

- Auditoria: an irregular hexagon with an area of $473 \mathrm{~m}^{2}$ and a height of 7 meters.

- $\quad$ Stage of area $71 \mathrm{~m}^{2}$ raised 0.7 meters from the auditoria area.

- Two galleries at the rear end on the upper floor and various other rooms.

For the modeling of the study site, the use of SketchUp was made so that the layout can be easily understood as well as can effectively used for multiple visual analyses. Furthermore, this software is quite simple and user-friendly so that exploring and working on this software for given work becomes simpler. The 3D model was developed considering the geometry of the hall such that the model would depict the real structure at a high level of accuracy. 


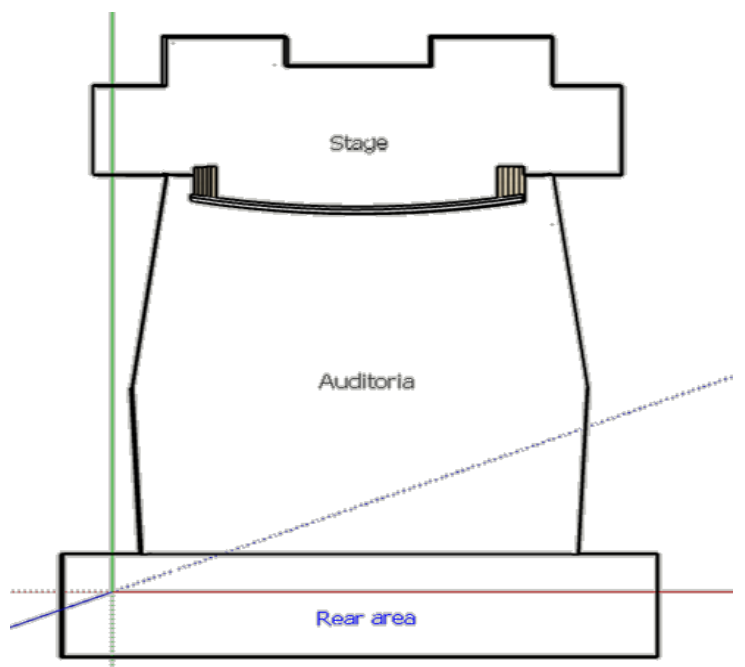

Figure 2. Layout diagram of existing MPH of the college

\section{Understanding from Users Perspectives}

POE starts with questionnaires and interviews. Interviews were conducted at different levels in a completely random manner to gather practical insights on the problems of the present lighting system. The survey allowed us to consider the stage as a different area with its illumination requirements. From the interviews with stakeholders such as the estate manager, engineer, technicians and the college administration, valuable data were gained, and it was learned that a renovation is being planned for the near future. The type of lamp that would be used in case of a renovation was also known, much as required by POE. At the end of the research, we would be able to give useful insight on the illumination to the estate manager of JNEC for the upcoming renovation of the hall.

A survey was carried out within a random sample of 105 students. Of the total number of participants, $80.9 \%$ of the participants were from the higher class of study who have spent more time on the campus. The same survey was distributed to a sample of 25 students from Cultural-Club members who were frequent users of the MPH, 14 teaching faculties of varying teaching experiences participated in interviews conducted in a random unofficial manner and it was found out that the lighting system in MPH needed some changes for better illumination of the hall.
At the end of the survey, we expect to identify more problems via the established dialogue and be able to work on the project as directed by the survey.

\section{Physical on-site measurement}

A Lux meter was used to carry out on-site measurements on 15/12/2020. The equipment used was a Konica Minolta T-10A illuminance meter, with a sensitivity of 0.01 lux to 299900 lux.

The measurements were taken at various points as shown in figure 3 and it was observed that the Illumination level was not met on even one point. The illumination was not uniform. These could be due to the many dysfunctional luminaries.

All required data for design and about luminaries were collected and tabulated.

Rough sketches were made, and measurements were taken using manually using measuring tape to aid in the designing in SketchUp. Measurements were done aiming at a high level of accuracy for the later computer design and simulation. This is one critical aspect of PBL incorporating the beneficiaries (users) being used from the initial stages for coming up with the best of the best understanding of the problems and working to its solution. Keeping the perspective of users for problems insight plays a major role in insightful knowledge and gathering practical situations which are worth for needful actions.

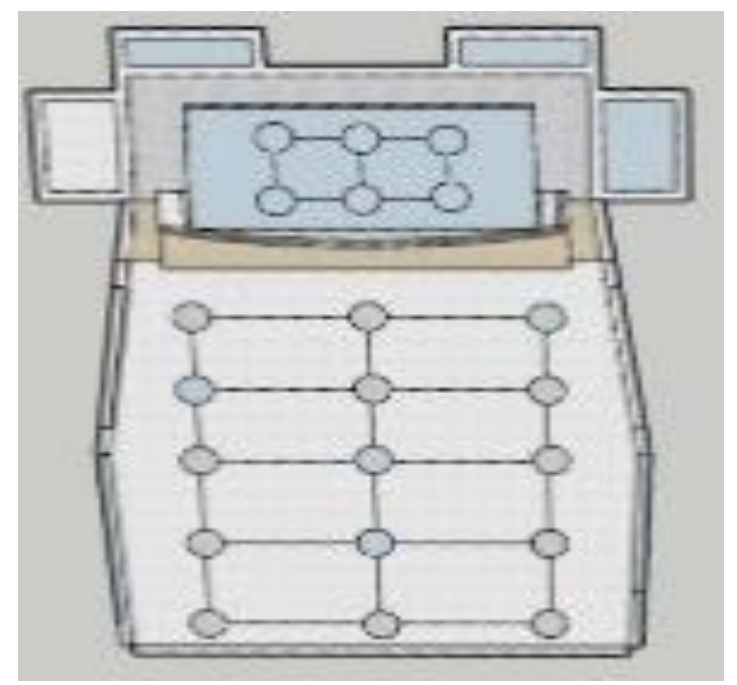

Figure 3. Reading point location on the site plan 
The above figure 3 is a planned layout that has been derived taking into consideration the actual reading points for measurement of illumination for the overall analysis of the lighting falling on the working plane.

\section{METHOD}

The study is based on secondary literature from relevant sources along with primary data that are obtained through the survey, site visit and analysis. The study considered the Problem Based Learning (PBL) approaches in overall problem framing, studies and conclusion. The research is more qualitative in nature and uses 'Post-Occupancy Evaluation (POE)' to align for PBL where two crucial investigation techniques of measurement and questionnaire are based for the overall study. Usage of freely available design software 'Sketchup' and illumination design software 'Dialux' were incorporated in this study for overall design and analysis.

\section{RESULTS AND DISCUSSION}

\section{Analysis from the survey}

Graphical representations of the survey are given below. Some observations are discussed below. most of the participants were satisfied. However, $9 \%$ of the participants felt the brightness in the MPH is not all acceptable. On the other hand, $11 \%$ of the participants were satisfied with the brightness level in the MPH.

Regarding the uniformity of illumination, $22 \%$ of the participants felt that the illumination is non-uniform. While $9 \%$ were fairly satisfied with the uniformity of illumination. Generally, the majority of the participants were not happy with the uniformity level. As shown in the visual comfort satisfaction chart, it can be concluded that the majority of the participants experienced the glare in the hall

The survey included 3 questions. The participants were asked to rate the brightness, uniformity of light and visual comfort of the MPH on a scale of 0-10. Finally, suggestions were asked to improve the lighting system in the future. The survey is quite critical as it reflected the practical situational analysis and the feedback obtained was more inclined to the need of enhancing the lighting system in MPH under study.
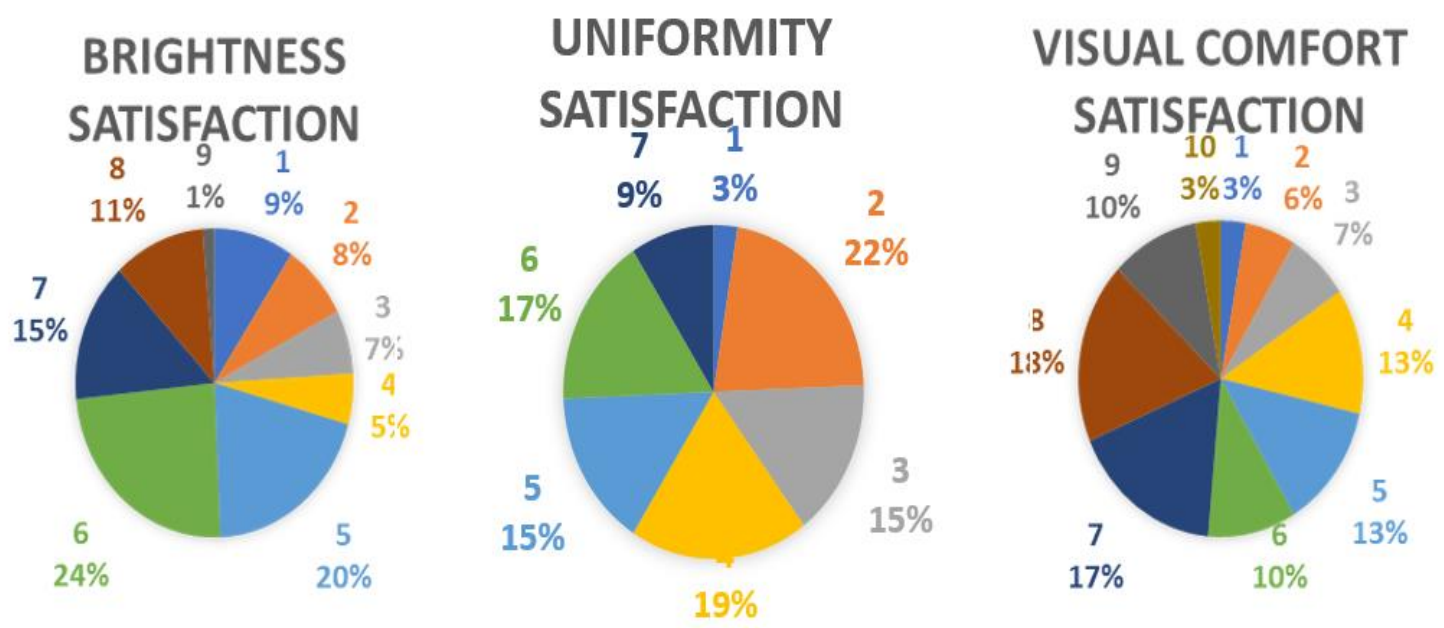

Figure 4. Survey results on the satisfaction level

Figure 4 is derived from the POE interventions three aspects of illuminations were surveyed. These aspects are brightness satisfaction, illumination uniformity satisfaction and visual comfort satisfaction. It is found as shown in figure 4 above that in terms of brightness,

\section{Analysis using standard calculation methods:}

Manual calculations were done as tabulated in Table 2 using the empirical formula;

Illumination in lux $=$

Utilisation factor $\times$ Maintenance factor $\times \sum$ No.of lamps $\times$ Lumen output 
Table 2. Energy Consumptions and Illumination level for present conditions and when all luminaires functioning.

\begin{tabular}{|c|c|c|c|c|c|c|c|c|c|}
\hline \multirow[b]{2}{*}{ Space } & \multicolumn{2}{|c|}{ Lamp specification } & \multicolumn{2}{|c|}{ Number of lamps } & \multicolumn{2}{|c|}{ Total wattage (W) } & \multicolumn{2}{|c|}{ Illumination (Lux) } & \multirow{2}{*}{$\begin{array}{l}\text { Number of } \\
\text { lamps } \\
\text { required to } \\
\text { meet the } \\
\text { illumination } \\
\text { level }\end{array}$} \\
\hline & 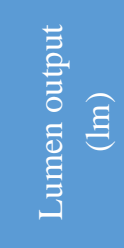 & 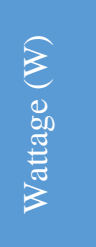 & 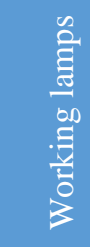 & 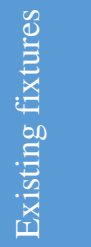 & 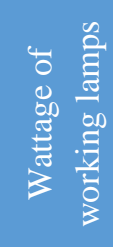 & 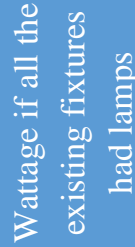 & 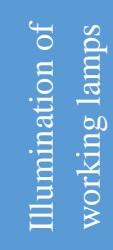 & 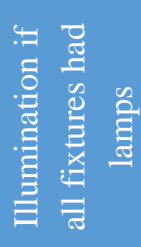 & \\
\hline \multirow{3}{*}{ Auditoria } & 810 & 9 & 33 & 63 & 297 & 567 & \multirow{3}{*}{46} & \multirow{3}{*}{97} & - \\
\hline & 5100 & 85 & 3 & 8 & 255 & 680 & & & - \\
\hline & 1800 & 18 & 2 & 2 & 36 & 36 & & & - \\
\hline \multirow{2}{*}{ Stage } & 810 & 9 & 8 & 8 & 72 & 72 & \multirow{2}{*}{60} & \multirow{2}{*}{60} & - \\
\hline & 2400 & 30 & 3 & 3 & 90 & 90 & & & - \\
\hline Back entrance & 810 & 9 & 1 & 2 & 9 & 18 & 5 & 10 & 20 \\
\hline Lefit gallery & 810 & 9 & 1 & 2 & 9 & 18 & 21.6 & 43.2 & 7 \\
\hline Right gallery & 810 & 9 & 1 & 2 & 9 & 18 & 21.6 & 43.2 & 7 \\
\hline Corridoor & 810 & 9 & 0 & 3 & 0 & 27 & 0 & 43.2 & 7 \\
\hline \multirow{2}{*}{$\begin{array}{c}\text { Women's Public } \\
\text { toilet }\end{array}$} & 810 & 9 & 2 & 2 & 18 & 18 & \multirow{2}{*}{120} & \multirow{2}{*}{120} & \multirow{2}{*}{4} \\
\hline & 1000 & 100 & 1 & 1 & 100 & 100 & & & \\
\hline \multirow{2}{*}{$\begin{array}{c}\text { Men's Public } \\
\text { toilet }\end{array}$} & 810 & 9 & 2 & 2 & 18 & 18 & \multirow{2}{*}{120} & \multirow{2}{*}{120} & \multirow{2}{*}{4} \\
\hline & 1000 & 100 & 1 & 1 & 100 & 100 & & & \\
\hline E-printing & 1800 & 18 & 1 & 2 & 18 & 36 & 28.2 & 56.4 & 5 \\
\hline Left corridor & 810 & 9 & 4 & 4 & 36 & 36 & 40 & 40 & 10 \\
\hline Right corridor & 810 & 9 & 4 & 4 & 36 & 36 & 40 & 40 & 10 \\
\hline
\end{tabular}

It was concluded that the illumination level would not be met even if all the lamps were working. However, since only the lamps of one room can be considered using the formula, the effect of light from other areas does not get accounted for. This can be later confirmed using the simulated results.

\section{Comparisons of lighting performance under present situations and when all lamp:}

Lighting performances of the existing system and considering all luminaries functional without the consideration of natural light were simulated in Dialux Evo.
To understand the uniformity, the light distribution of the rooms was considered. Had all luminaries been functioning, the illumination level in the auditoria would be met but would be subjected to high glare levels. Light distribution of the rooms was considered. Had all luminaries been functioning, the illumination level in the auditoria would be met but would be subjected to high glare levels.

From the calculation as well as analysis, it is observed that in the auditorium as well as main hall and stage there are requirements for increasing the illumination level to meet the standard. 
JOURNAL OF SCIENTIFIC, TECHNOLOGY AND ENGINEERING RESEARCH

Bilim, Teknoloji ve Mühendislik Araştırmaları Dergisi, (2021) - 2(2): 89-100

ISSN : 2717-8404 https://dergipark.org.tr/en/pub/jster

Table 3. Comparison of lighting performances of the present situation with that of all luminaries functioning.

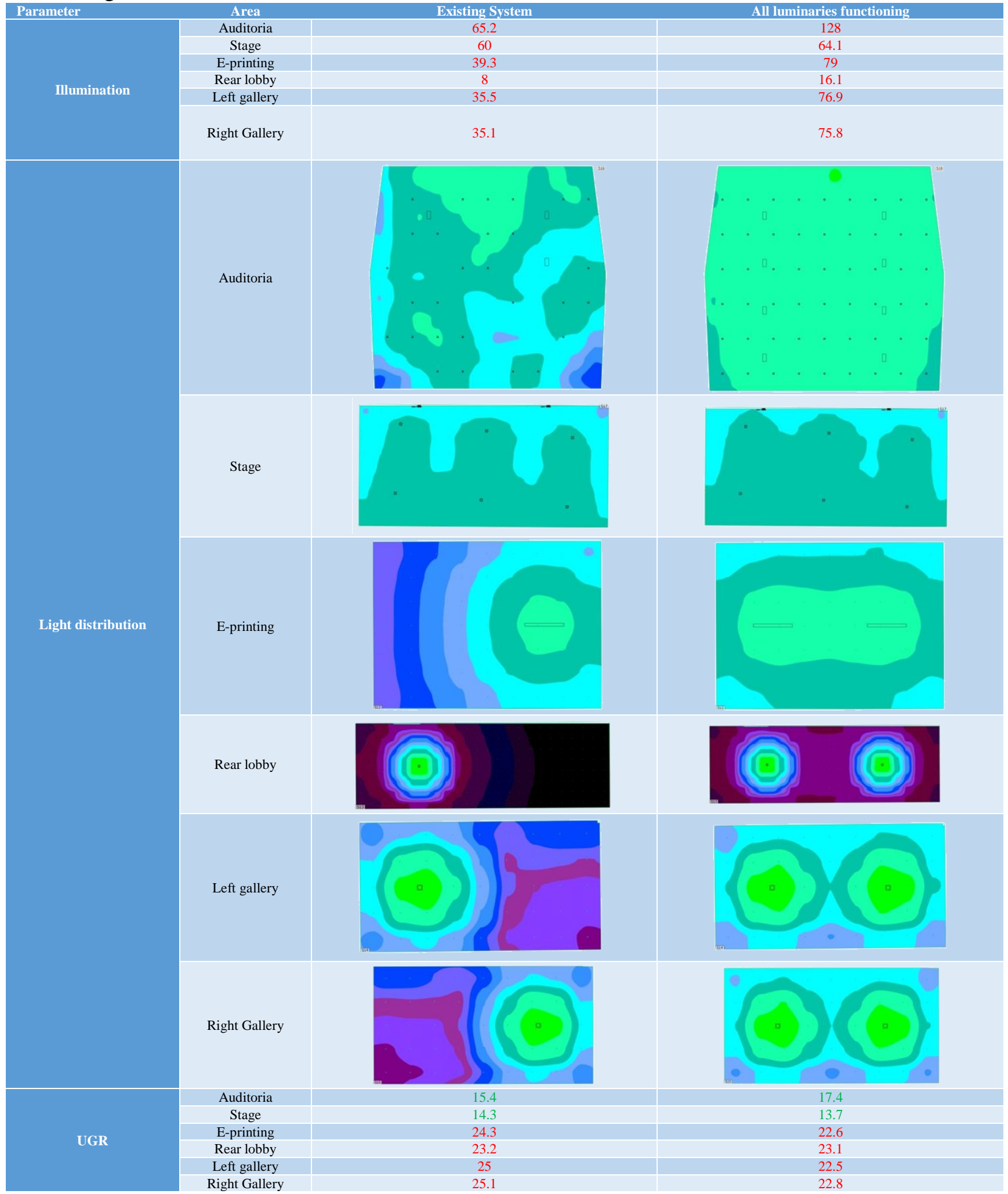




\section{RECOMMENDATION}

Multiple cases can be looked into to make holistic action in incorporating the energy-efficient retrofits in the MPH. A couple of cases are recommended as follow:

\section{Case 1. Enhancing illumination through increased retrofits}

The lighting distribution in Stage and Auditoria is shown as shown in figure 5 below.
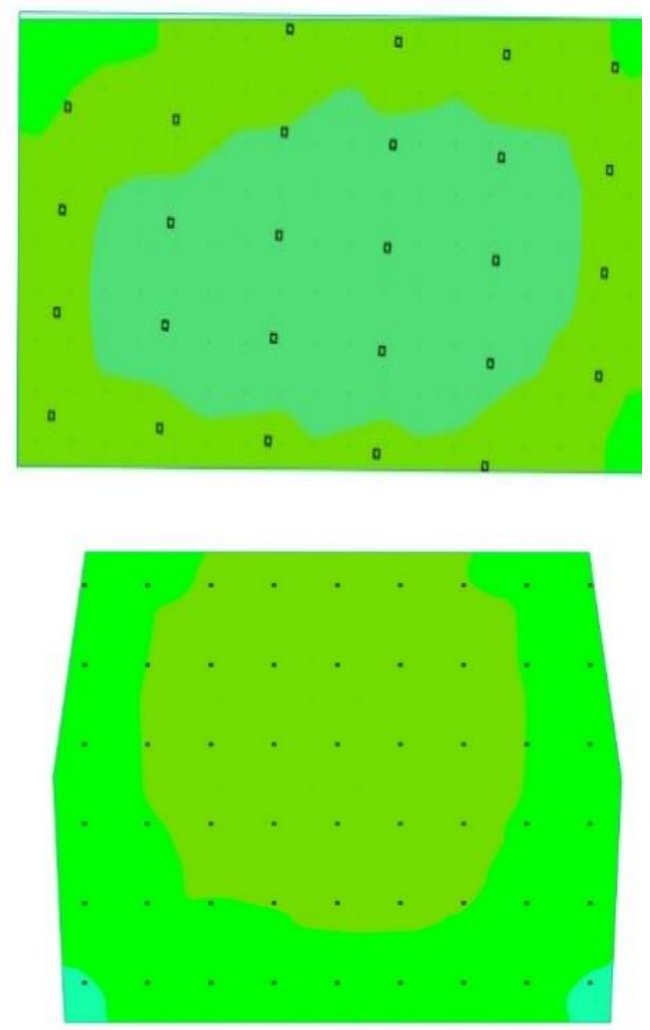

Figure 5. 5a. Lighting Distribution for Stage, 5b. Lighting distribution for auditoria

In an auditorium space, the addition of around 46 lux is required to meet the illumination level. This additional 46 lux could be met by increasing the lumen output by 52000 lumens. 5200 lumens can be achieved by any combination of lamps by adding sums of the product of lumen output and number of lamps.

For times when the hall functions as a badminton court, the illumination required would be met by increasing the lumen output by 34000 lumens. 34000 lumens can be achieved by placing 8 floodlights of 4200 lumens right about the badminton area, connected in such a way that it is only turned on while playing badminton. For the stage under the present scenario, the illumination is short by 167 lux which can be overcome by increasing the lumen output by 25000 lumens. 25000 lumens can be achieved by using 6 floodlights of 4200 lumens.

\section{Case 2. Enhancing illumination through changes of luminaries}

Though the illumination level in the Auditoria, stage and when the auditoria functions as a badminton facility are met when the number of luminaires used is increased. However, it is seen that the glare requirement is not met either in an existing system or when the number of lamps is increased. Therefore, instead of replacing the existing luminaires with luminaries of the same type, if luminaries of $24 \mathrm{~W}$ and 1680 Lumen (as suggested by the estate manager) is to be used then Stage and Auditoria if uniformly illuminated and the glare level is within the permissible range.

\section{Case 3. Enhancing illumination through the enhanced window for natural lighting}

The existing system with its window size doubled gives the following result. The increasing window size can be an expensive renovation but the new design could have larger windows. Various research done on window size suggests that the windows must at least be $6 \%$ of the floor area and must not exceed $25 \%$. Having a higher window to floor ratio increases the daylight factor. For a 3\% daylight factor, a window to floor ratio (WFR) must be kept at $10 \%$ [15]. The WFR for the MPH under the case study is only $3 \%$. 


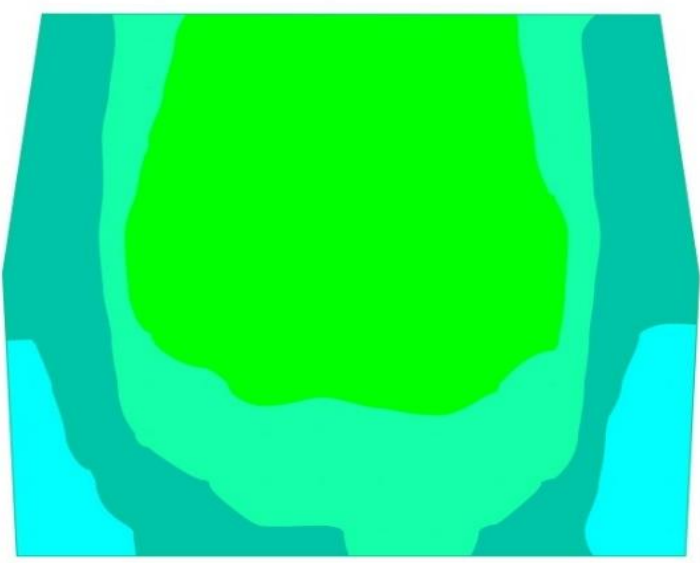

Figure 6. Lighting distribution in auditoria

It was observed from figure 6 above that an average of around 100 lux is met with this proposal. Thus, onethird of lamps can be turned on during the daytime.

Case 4. Enhancing illumination through the use of light domes OR translucent roofs OR light tunnels

The existing system with 30 light domes as shown installed above the auditoria, gives the light distribution as shown in Figure $7 \mathrm{~b}$.
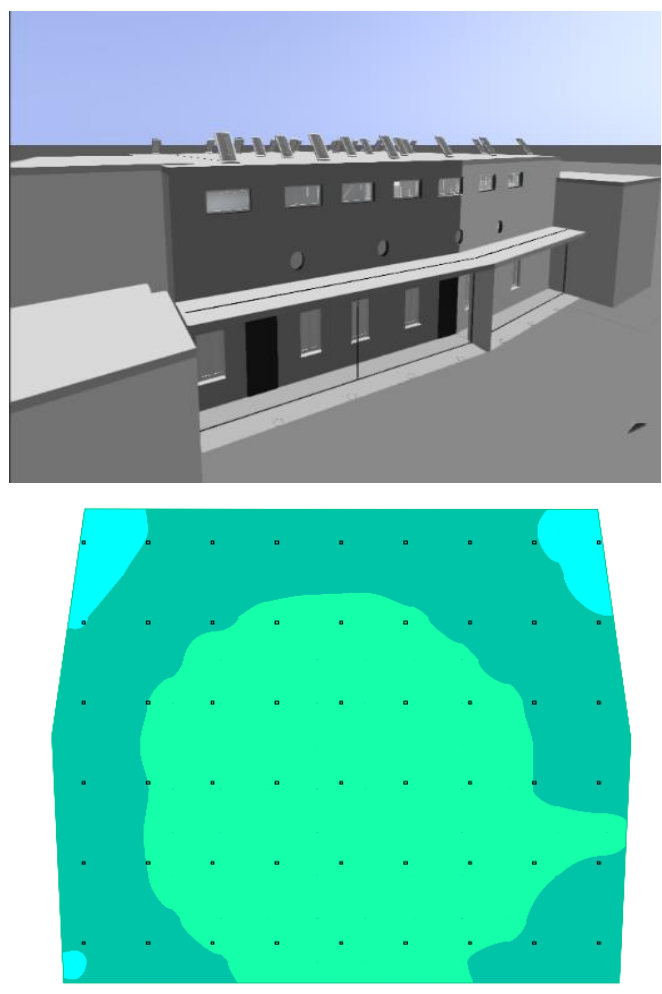

Figure 7. 7a. MPH with 30 domes arrangement, 7b. Light distribution on auditoria
The existing system with 10 translucent roofs installed above the auditoria, gives the following result of lighting distribution as shown in Figure 8b.
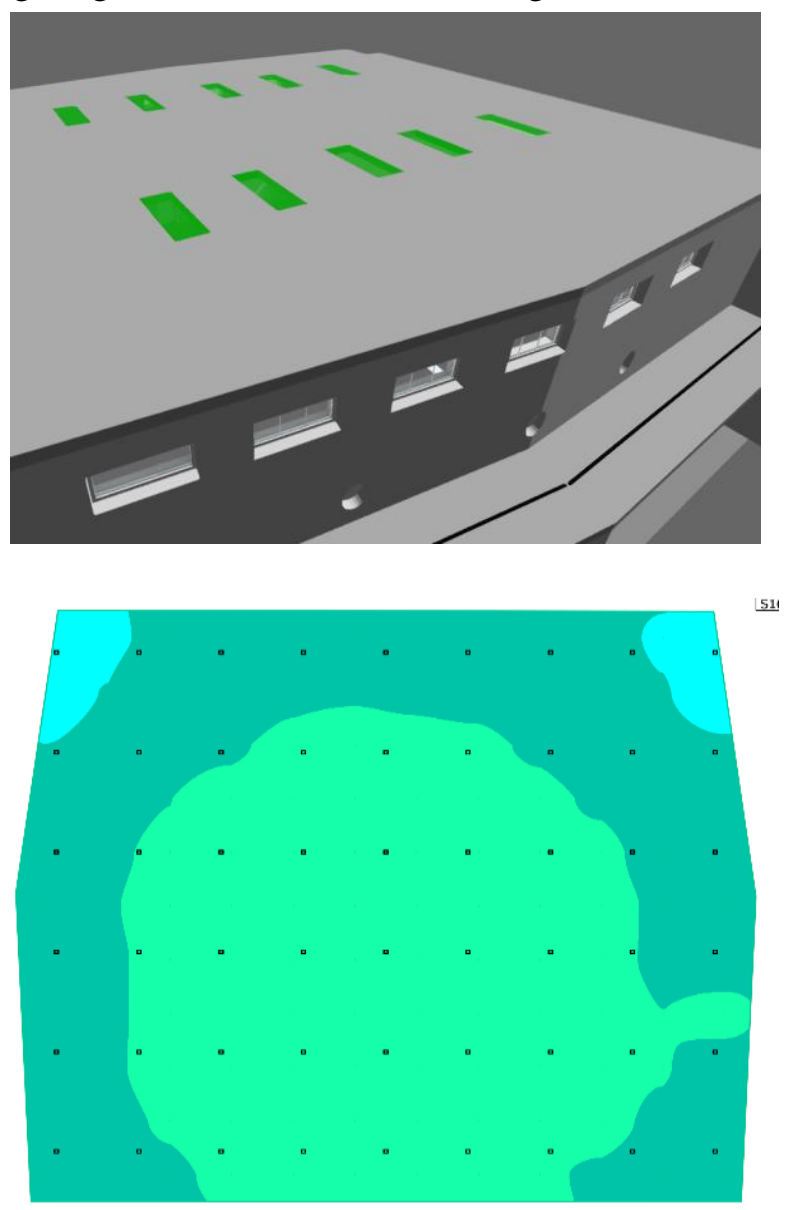

Figure 8. 8a. MPH with 10 translucent sheets arrangement, 8b. Light distribution on auditoria

As shown from the figure $8 \mathrm{~b}$ above, it is possible to turn on just one-third of the lamps and the average of around 100 lux can be met from the natural lighting arrangements.

The existing system with 30 light tunnels installed above the auditoria, gives the following result of lighting distribution as shown in Figure 9b below. As shown from the figure $9 \mathrm{~b}$ above, it is also possible to turn on just one-third of the lamps and the average of around 100 lux can be met from the natural lighting arrangements. Some of the essential illumination requirements can be met from the natural light in all of these three options which will result in minimal usages 
of artificial light during daytime use of MPH auditoria as it can meet about 100 lux of illumination.
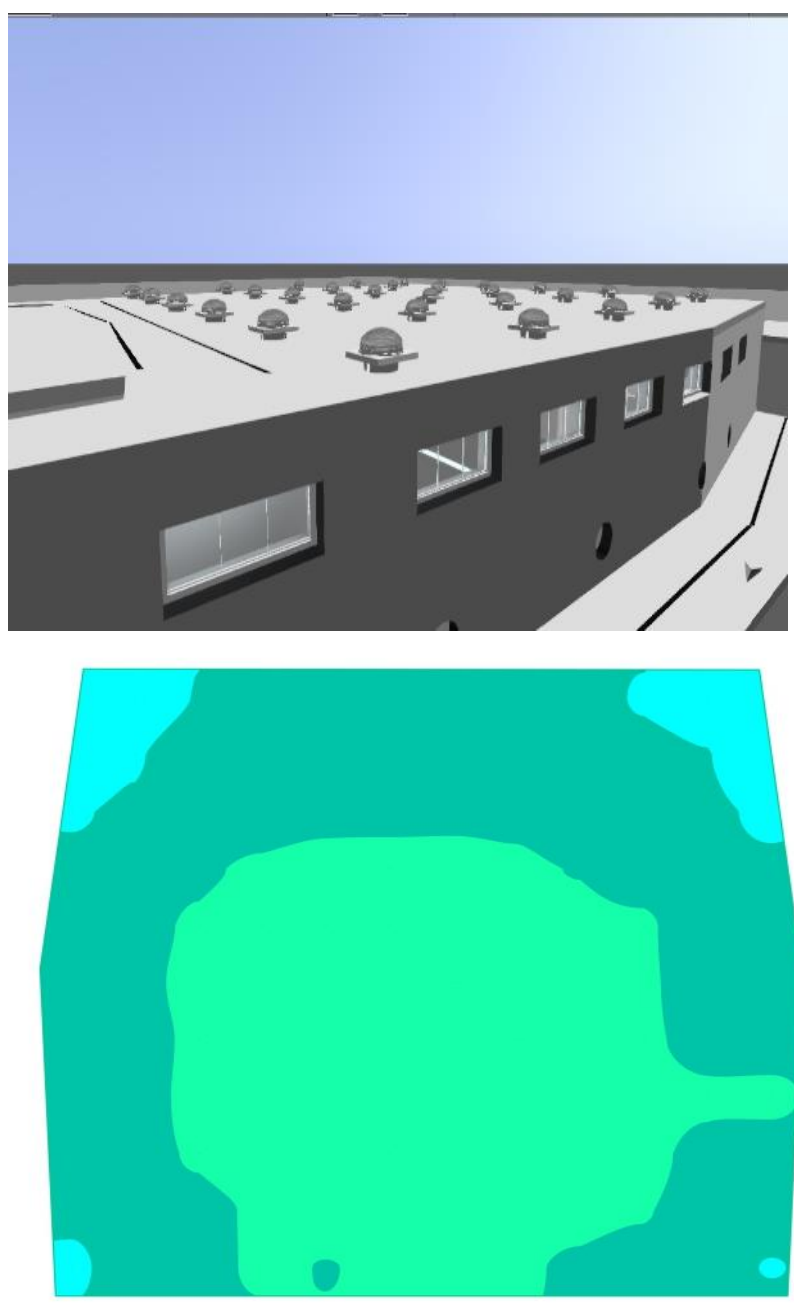

Figure 9. 9a. MPH with 30 light tunnels arrangement, 9b. Light distribution on auditoria

The combination of these approaches can still be more beneficial in trapping the maximum benefits of artificial light. Though such measures in the time of renovations are costly, those options are always beneficial in trapping the natural lighting for efficient illumination design. It needs to be noted that there should always be efficient illumination luminaires installed so that the required illuminations are not deprived during nighttime. These three options as stand-alone or in combinations are only for day usage lighting efficiency options through the utilization of natural light.

\section{CONCLUSION}

Starting from the observations that were confirmed by surveying, the focus was given to the glare level, illumination level and the uniformity in the level of illumination in MPH. Firstly, the illumination level would be met if all the lighting fixtures currently present were to be made functional. However, the glare level would be beyond the permissible level. For this case, installing better lamps and using greener alternatives like using light tubes, domes, larger windows, and translucent sheets would be more effective in providing better illumination in the MPH. If a part of MPH is to function as a badminton facility, 8 flood lamps of 4200-lumen output can be used, turning it on as and when required. It was found out that 15 domes or 15 light tubes or 5 translucent sheets produce one-third of the required illumination, i.e.., an equivalent of 50 lux. Domes and light tubes are more capital intensive. Translucent sheets are more efficient in terms of cost. A window to floor ratio of $6-25 \%$ is recommended.

Finally, a PBL approach can be used as an efficient tool in terms of realizing the practical problem which can be incorporated with rigor in coming up with multiple options in countering the problems. In the case of efficient illumination design and incorporations, it is always crucial to study illumination fulfillment with the best of the best efficient luminaires available in the market along with tapping of the maximum potential of natural light.

\section{CONFLICTS OF INTEREST}

This research has no conflict of interest involved with any individual as well as institution. All the contributions are well referred and acknowledged the sources where necessary.

\section{RESEARCH AND PUBLICATION ETHICS}

All contributing authors, as well as contributors, are acknowledged and there is no ethical issues with plant or animals involved in this research work.

\section{ACKNOWLEDGMENT}

For this work, the authors would like to acknowledge CLEES for necessary support. Also, the authors would like to acknowledge PBL South Asia project co-funded by the European Union which is underway in the college where the 
option of integrating PBL in teaching and learning is incorporated and the teams are able to benefit from it.

\section{REFERENCES}

[1] Costanzo, V., Evola, G., \& Marletta, L. (2017). A review of Daylighting strategies in schools: State of the art and expected future trends. Buildings, 7(4), 41. doi.org/10.3390/buildings7020041

[2] Yangzom, K., $\quad$ Bhattarai, H., $\quad$ Choki, S., Choden, P., \& Yangden, S. (2021). Energy efficient lighting design - A case study of jigme namgyel engineering college. Journal of Applied Engineering, Technology and Management, 1(1), 1421. doi.org/10.54417/jaetm.v1i1.20

[3] Zhao, G. (2020). The influence of natural light on the design of electrical lighting -taking Liaohe art Museum as an example. Journal of Physics: Conference Series, 1601(2), 022009. doi.org/10.1088/1742-6596/1601/2/022009

[4] ITeh standards. (2011). iTeh Standards. https://standards.iteh.ai/catalog/standards/c en/d7c62c9a-95ac-4ed8-9a40-862805aa5afc/en12665-2011

[5] Preto, S. (2019). Dynamic facades: Optimization of natural light at workplaces. Advances in Intelligent Systems and Computing, 392402. doi.org/10.1007/978-3-030-20151-7_37

[6] Jamala, N., Rahim, R., \& Mulyadi, R. (2019). Analysis of natural light distribution in the building. IOP Conference Series: Materials Science and Engineering, 619(1), 012024. doi.org/10.1088/1757-899x/619/1/012024

[7] Schmal, C., Herzel, H., \& Myung, J. (2020). Clocks in the wild: Entrainment to natural light. Frontiers Physiology, 11.

doi.org/10.3389/fphys.2020.00272

[8] Balocco, C., Cecchi, M., \& Volante, G. (2019). Natural lighting for sustainability of cultural heritage refurbishment. Sustainability, 11(18), 4842. doi.org/10.3390/su11184842

[9] MoWHS, RGoB. (2013). Bhutan Green Building Design Guidelines. Ministry of Work and Human Settlement. https://www.mowhs.gov.bt/wp-
content/uploads/2014/05/Bhutan-GREEN-BuildingDesign-Guidelines-PDF-for-website-FI.pdf

[10] Thompson, A. D. (2006). The worth of natural light. Journal of Building Appraisal, 2(1), 4451. doi.org/10.1057/palgrave.jba.2940037

[11] BREEM.(2011). Hea 01, Visual Comfort. https://www.breeam.com/BREEAMUK201 4SchemeDocument/content/05_health/hea01_nc.htm

[12] Michael, A., \& Heracleous, C. (2017). Assessment of natural lighting performance and visual comfort of educational architecture in Southern Europe: The case of typical educational school premises in Cyprus. Energy and Buildings, 140, 443457.

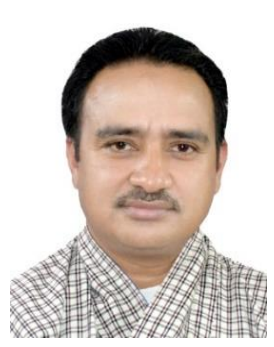

Bhattarai, H. was born in Bhutan, in 1976. He received the Diploma in Electrical Engineering from Royal Bhutan Polytechnic, B.E. Electrical Engineering from College of Science and Technology, both from Bhutan and M.Tech. in Power and Energy System from National Institute of Technology, Karnataka, India. $\mathrm{He}$ is working as faculty of the Department of Electrical Engineering since 2006 which is under Jigme Namgyel Engineering College, Royal University of Bhutan, Bhutan.

Currently working as Dean Research \& Industrial Linkages. Before working as Dean, he has served as Head of Electrical Engineering. He was also Project Manager of for "Promoting energy-efficient lighting in Nepal and Bhutan (ELNAB)" which was completed in Jan-2019 and also the Project Manager and Advisory Committee of ongoing projects on "Enhancing Problem Based Learning for South Asian Universities" both of which are funded by the Erasmus Project of European Union. He has taught in the Department of Electrical Engineering since 2006 and has mostly been associated with teaching mostly power systems, energy management \& auditing, power electronics, renewable energy, high voltage engineering, research methodology and entrepreneurship.

Hemlal research area of interests includes power engineering and energy systems with major focus on Renewable Energy and has been associated with many international conferences/publications including IEEE as program committee, keynote speaker and reviewer. He is currently the focal for Thematic Working Group (TWG) on Energy from Bhutan for ICIMOD. 